\title{
Politizaciones fronterizas: el "lugar" de las identidades sexuales disidentes en los espacios de la ciudad
}

\author{
Laura Recalde Burgueño \\ Universidad de la República, Uruguay. \\ laurarecalde4@gmail.com
}

\section{Resumen}

El presente artículo es resultado de una investigación que buscó indagar sobre las formas de politización de las identidades sexuales y de género disidentes en ciudades del interior en los países de Uruguay y Argentina. Este texto recoge algunos de los hallazgos obtenidos y tiene como objetivo analizar cómo son politizadas las identidades disidentes por parte de lxs sujetxs en distintos lugares de la ciudad de Rivera (Uruguay). Partimos de preguntarnos cómo, en un contexto de garantías legales para esta población como es el caso de Uruguay, lxs sujetxs organizan su experiencia identitaria, qué fronteras espaciales y simbólicas podemos encontrar y cómo repercuten éstas en las trayectorias de las personas en su vida cotidiana y en particular en el goce de sus derechos.

La metodología utilizada, de índole cualitativa, articula la realización de entrevistas en profundidad y la observación participante, con una perspectiva etnográfica. Los hallazgos encontrados muestran cómo las formas de politizar las identidades por parte de lxs sujetxs no son homogéneas sino oscilantes, fronterizas. Se observa además cómo en los lugares de la ciudad se reproducen imaginarios sociosexuales excluyentes y desiguales basados en un orden cisexista y heterosexual que limita el ejercicio de los derechos humanos.

Palabras clave: politización, identidades sexuales y de género disidentes, lugares de la ciudad. 


\title{
Border politicizations: the "place" of dissident sexual identities in city spaces
}

\begin{abstract}
This article is the result of an investigation that sought to investigate the forms of politicization of dissident sexual and gender identities in inner cities in the countries of Uruguay and Argentina. This text gathers some of the findings obtained and aims to analyze how disident identities are politicized by subjects in different parts of the city of Rivera (Uruguay). We start by asking ourselves how, in a context of legal guarantees for this population, as is the case in Uruguay, the subjects organize their identity experience, what spatial and symbolic boundaries we can find, and how they affect these in the trajectories of people in their daily lives and particularly in the enjoyment of their rights.

The methodology used, of a qualitative nature, articulates the conduct of in-depth interviews and participant observation, with an ethnographic perspective. The findings found show how the ways to politicize identities on the part of the subjects are not homogeneous but oscillating, bordering. It is also observed how are reproduce, in city locations, exclusive and unequal sociosexual imaginaries based in cissexual and heterosexual order that limits the exercise of human rights.
\end{abstract}

Key words: politicization, dissenting sexual and gender identities, places of the city.

Fecha de recepción: 10 de octubre de 2019.

Fecha de aprobación: 16 de febrero de 2020. 


\section{Introducción}

El presente artículo es resultado de una investigación que llevé adelante en los años 2016 y 2017 denominada: "Las fronteras de la identidad. Politización de las identidades sexuales disidentes en ciudades del interior"1. La misma tuvo como objetivo analizar cómo se politizaban las identidades sexuales y de género ${ }^{2}$ disidentes en ciudades del interior, específicamente en Rivera ${ }^{3}$,(Uruguay) y Córdoba ${ }^{4}$, (Argentina).

El presente texto da cuenta de algunos de los hallazgos obtenidos en dicha pesquisa específicamente en el departamento de Rivera, Uruguay. Para este artículo nos preguntamos cómo, en un contexto de garantías legales para esta población como es el caso de Uruguay, lxs sujetxs con identidades sexuales y de género disidentes politizan sus identidades en los espacios de la ciudad, qué fronteras espaciales y simbólicas podemos encontrar y cómo repercuten éstas en las trayectorias de las personas en su vida cotidiana y en particular en el goce de sus derechos.

\section{Contexto de la investigación}

Desde hace más de diez años Uruguay comenzó un camino de consecución de garantías legales para la población sexual disidente. Con la asunción al gobierno del Frente Amplio ${ }^{5}$ en

1 Este artículo es resultado de la investigación que llevé adelante para mi tesis de Maestría en Ciencias Humanas opción Estudios Latinoamericanos (Fhuce-UdelaR) la misma fue financiada por la Agencia Nacional de Investigación e Innovación (ANNI, Uruguay).

2 En el presente artículo se ha optado por denominar a las identidades: "sexuales $y$ de género disidentes" agregando explícitamente "y de género", denominación ausente en la investigación original, por distintos motivos. Por un lado, para explicitar que se está incluyendo la dimensión de género en el análisis de dichas identidades y, por otro, porque entiendo la relación, muchas veces compleja, entre el sexo y el género en este tipo de análisis y no quisiera que se interprete que esta dimensión está ausente. Dentro de la identidad sexual de las personas entendemos que están incluidas dimensiones como la del género, la expresión del género, la orientación, la eroticidad, entre otros elementos. Siguiendo la línea teórica de Judith Butler $(2007,2010)$ la materialización de los cuerpos sexuados y generizados obtiene su estatus de inteligibilidad a través de una matriz heterosexual, cultural, lo cual implica una serie de tecnologías, en las que se encuentra el sexo (dentro del dispositivo de la sexualidad), y procesos por los cuales la materialidad del cuerpo es significada y materializada como tal. Por tanto, al hablar de identidades sexuales se hace alusión a esa matriz compleja de inteligibilidad a partir de la cual los cuerpos se materializan, cuerpos que son sexuados y generizados por la misma matriz; por ello se mantiene el título original del artículo que no pudo ser modificado posteriormente por cuestiones editoriales. Sobre las implicancias entre sexo y género se puede consultar el artículo "Entre fícciones y subversiones. Pensando los cuerpos sexuados y generizados." (Recalde \& Gómez: 2018) disponible en: https://www.academia.edu/37026918/Entre_ficciones_y_subversiones._Repensando_los_cuerpos_sexuados_y_g enerizados que hace énfasis en éstas y otras cuestiones.

3 Departamento de Uruguay.

4 Provincia de Argentina.

5 Fuerza política de Uruguay que agrupa a distintos partidos políticos. 
el año 2005, y en conjunto con el trabajo que venían desarrollando distintas organizaciones sociales, se fue desplegando una agenda de "nuevos" derechos para poblaciones postergadas, aprobándose una serie de leyes que antes no habían sido contempladas por el Estado.

Las legislaciones conseguidas, desde aquellos años, como por ejemplo el Matrimonio Igualitario (Ley $\mathrm{N}^{\circ}$ 19.075) en 2013 y la Ley de Identidad de Género (Ley $\mathrm{N}^{\circ}$ 18.620) en 2009, actualmente derogada por la Ley Integral para personas Trans ${ }^{6}$ (Ley $N^{\circ}$ 19.684), entre otras $^{7}$, han marcado un antes y un después en cómo la sexualidad disidente ha sido puesta en el debate público en el país.

La reivindicación por el Matrimonio Igualitario en Uruguay fue heredera de países como España (2005) y Argentina (2010) que habían aprobado previamente esta ley. En Uruguay en la ley se suprimen palabras como: "marido" y "mujer", sustituyéndose por: "cónyuges" o "contrayentes", y se introducen además ciertos cambios que responden a nuestro contexto en particular. Se incorpora la causal de divorcio por sola voluntad de unx de lxs contrayentes (no por sola voluntad de la mujer como era anteriormente), la elección del orden de los apellidos de lxs hijxs, permitiendo a las parejas heterosexuales que el apellido materno pueda ir primero, así como otras garantías para parejas del mismo o diferente sexo en relación a la parentalidad (Sempol, 2013).

Por su parte, la Ley de Identidad de Género (2009) si bien fue un gran avance para la población trans ${ }^{8}$, en la práctica requería, para su efectivización, de un proceso judicial que impedía su consecución por los costos materiales que implicaba. A partir de la aprobación de la Ley Integral para personas Trans (2018) el trámite deja de ser judicial y se introducen otros cambios significativos como por ejemplo se incorpora una pensión reparatoria para personas trans que sufrieron vulneraciones en sus derechos humanos en la última dictadura militar, así como una serie de artículos que incorporan garantías para el acceso al trabajo, salud, vivienda, formación y soluciones habitacionales.

6 Ley disponible en: https://www.impo.com.uy/bases/leyes/19684-2018.

7 Otras leyes y reglamentaciones importantes. 2004: Ley $N^{\circ}$ 17.817: Lucha Contra el Racismo, la Xenofobia y la Discriminación. 2007: Se crea la Comisión Honoraria contra el Racismo y la Xenofobia. 2008: Ley N. ${ }^{\circ}$ 18.246. Unión Concubinaria (incluye a las parejas del mismo sexo). Ley $\mathrm{N}^{\circ}$ 18335: Derechos y Obligaciones de Pacientes y Usuarios de los Servicios de Salud. 2009: Decreto que elimina orientación sexual para el ingreso a las fuerzas armadas. Ley $\mathrm{N}^{\circ}$ 18590: Reforma del sistema de adopciones por parte de parejas del mismo género. 2013: Ley N 19.167 Regulación de las técnicas de Reproducción Humana Asistida (incluye parejas del mismo sexo).

8 Por "trans" se entenderá, siguiendo a Blas Radi (2018) a aquellas personas que se identifican con un género diferente al asignado, es un concepto operativo una "campana semántica", en donde podemos identificar por ejemplo a personas travestis, transexuales y transgéneros pero también otras. De todas maneras, el término "trans" no atiende en su definición a la diversidad que dicho término contempla y que no puede clausurarse. 
Se visualiza cómo con el paso del tiempo se mantiene, por parte de distintos colectivos sociales y sectores políticos, una búsqueda constante de mejores legislaciones y acceso a derechos para la población sexual y de género disidente.

\section{Caracterización del campo: Rivera, Uruguay}

Uruguay posee un gobierno descentralizado, dividido en diecinueve departamentos y su capital es la ciudad de Montevideo. Según la Constitución de la República Oriental del Uruguay el gobierno departamental posee tres niveles de gobierno: Ejecutivo (Intendente), Legislativo (Junta Departamental) y Municipal (Municipios con especificidad territorial) y su gobierno tiene alcance solamente en la superficie del departamento. En lo que refiere a la relación con los entes descentralizados del Estado los departamentos pueden coordinar con éstos su accionar en el territorio. En lo que refiere a la seguridad y administración de justicia no es autónomo y depende de las respectivas instituciones centrales ${ }^{9}$.

Los departamentos poseen un presupuesto propio. Según el estudio: "Diagnósticos y diferentes visiones sobre la dinámica socio-económica en la Región Noreste” (2012) la región comprende los departamentos de Artigas, Rivera, Cerro Largo y Tacuarembó y es la región más alejada de la capital del país habitando en ella un 10,5\% de la población. Asimismo, según el Índice de Desarrollo Humano llevado adelante por el PNUD (CCI-UdelaR, 2012), la región Noreste, presenta una situación de menor desarrollo respecto al resto de los departamentos, situación que tiene como correlato que los ingresos de los hogares estén por debajo del ingreso promedio y que la pobreza sea otro factor de incidencia significativa en la región. Según datos del censo del $2011^{10}$ (INE, 2011) Rivera tiene una población de 103.473 personas de las cuales 95.871 reside en la capital del departamento. Está a una distancia de Montevideo de $500 \mathrm{~km}$ y posee frontera seca con Santana do Livramento- Brasil.

\section{Metodología}

La estrategia metodológica para la investigación se desarrolló en dos momentos. En el primero se procedió a una búsqueda documental y recopilación de la producción en torno a las identidades sexuales y de género disidentes en Uruguay desde el año 2005. Se definió así el contexto general del tema y se delinearon ciertos hitos en el periodo a estudiar. $\mathrm{Y}$ un

9 Fuente: Constitución de la República Oriental del Uruguay. Disponible en: https://parlamento.gub.uy/documentosyleyes/constitucion.

10 http://www.ine.gub.uy/web/guest/censos 
segundo momento, en el que se llevó adelante el trabajo de campo de corte etnográfico en las ciudades seleccionadas. Se realizaron las entrevistas y se llevó adelante la observación participante.

Las entrevistas seleccionadas para este artículo corresponden a personas que se autoidentifican dentro de las identidades sexuales y de género disidentes (LGBTIQ u otras) y desde ese posicionamiento relatan sus experiencias vitales. Por lo tanto, las categorías identitarias con las que serán denominadas las personas entrevistadas son "nativas", es decir provienen de lxs mismxs sujetxs.

Se realizaron un total de diez entrevistas en la ciudad de Rivera de las cuáles fueron seleccionadas aquellas que permitieran abordar el objetivo propuesto en este artículo desde distintas aristas. Las entrevistas contaron en general con una pauta guía, pero no fueron totalmente dirigidas de manera que cada persona pudiera ahondar espontáneamente en sus respuestas. Se utilizó la técnica de "bola de nieve"11 para contactar a lxs entrevistadxs cuyos nombres en el texto han sido modificados para respetar su confidencialidad.

Además de las entrevistas mencionadas se realizó observación participante en distintas instancias, por ejemplo: actividades realizadas por los colectivos LGBTIQ locales, participación en comisiones de género de la ciudad, presentaciones de libros de la temática LGBTIQ, tránsito por la ciudad con lxs entrevistadxs, entre otras. Observaciones que fueron registradas posteriormente en el diario de campo de la investigación y luego incorporadas al análisis. De manera general la investigación tuvo un enfoque etnográfico que, si bien no tiene como resultado un texto etnográfico, sí intentó dar cuenta, desde su acepción de "enfoque" y "método", de cómo lxs actorxs dan sentido a ciertos hechos y de cómo también la investigadora se posiciona en cuanto a la descripción e interpretación de los acontecimientos (Guber, 2001).

Para el análisis de las entrevistas se utilizaron distintas técnicas de análisis cualitativo, primeramente, análisis de contenido, que tuvo como objetivo analizar cómo se construye el relato sobre ciertos temas, la frecuencia numérica y repetición de conceptos centrales, el modo en que los mismos aparecieron y las concatenaciones de sentido de los mismos, entre otros elementos. Fue usado además el método de cadenas nocionales, que tiene como objetivo

11 Técnica de investigación utilizada para seleccionar la población en una investigación. La selección de los participantes se desarrolla a partir de lxs propixs sujetxs involucradxs que por el conocimiento que poseen de los rasgos de la población a abordar van realizando contactos tipo red, "bola de nieve", unxs a partir de otrxs. 
analizar las cadenas significantes que lxs entrevistadxs adjudican a ciertas acepciones o sucesos que son relevantes para el tema de investigación, logrando de esta forma identificar conceptos clave y también asociaciones de sentido por parte de lxs entrevistadxs.

\section{Las identidades sexuales y de género disidentes}

La sexualidad humana es una actividad que está presente en todas partes de la vida en sociedad (Guasch, 1993; Rubin, 1989; Vance, 1997; Weeks, 1998) excediendo la dimensión biológica de lxs sujetxs, necesitándola, pero no remitiéndose solamente a sus aspectos psíquicos y/o físicos (Rubin, 1989: 15). La sexualidad posee una historia social y política, una historia de represión, productividad y construcción en el tiempo que tiene distintas particularidades según los contextos políticos y sociales.

Siguiendo a Vance (1997) las identidades sexuales y de género son una construcción social que se relacionan con las formas en que como sociedad e individuos experimentamos y entendemos la misma. Las maneras de conceptualizar la sexualidad, incluidas las identidades sexuales y de género, hacen referencia al dispositivo de la sexualidad, es decir, a las relaciones de poder y a las maneras en que se gestiona y administra socialmente (Foucault, 2011). La sexualidad como construcción social es un campo político de negociación y lucha en donde intervienen distintos actores (Weeks, 1998: 64).

Hacer referencia a la politización de las identidades sexuales y de género implica entonces, por un lado, analizar el carácter político de la sexualidad, su continua gestión y administración (Foucault, 2011), sus estrategias y modalidades, y por otro, a las formas de organización de la experiencia identitaria disidente, desde distintos espacios y marcos interpretativos (Argüello, 2013). Las personas al politizar sus identidades, lo hacen desde ciertas categorías identitarias, desplegando una serie de estrategias y modalidades en relación a las mismas en diferentes ámbitos de su vida.

La identidad abarca muchas dimensiones de la existencia, incluida la sexualidad, siendo un concepto útil para pensar cuestiones como la raza o la cultura en las sociedades actuales. Hall (2003) propone pensar la identidad a través de la figura de la "sutura". Una articulación entre aquellos posicionamientos teóricos que centran su mirada en la producción subjetiva del sujeto, y sus procesos de identificación como por ejemplo el psicoanálisis lacaniano, y aquellxs que la centran en las prácticas discursivas, como por ejemplo Foucault. El concepto de identidad acepta que las identidades no son únicas, sino fragmentadas y múltiples, 
construidas de diversas maneras por discursos y prácticas, sujetas al cambio y la transformación (Hall, 2003: 17).

Las identidades se construyen en el discurso, producidas en contextos históricos e institucionales y en relaciones específicas de poder. Entender a las identidades como "suturas" permite realizar una articulación entre los discursos y prácticas sociales que designan los modos posibles de "devenir" de lxs sujetxs y aquellos procesos subjetivos que permiten efectivamente que esas posiciones sociales sean asumidas y materializadas en cuerpos concretos, aunque nunca de una manera total. La identificación subjetiva como fue mencionado designa posiciones que lxs sujetxs deben tomar en su formación como tales teniendo presente que se trata de representaciones en el discurso; una división desde un otro que nunca puede ser idéntica a los procesos subjetivos.

Si la identidad preserva conceptos estables respecto al sexo, el género y la sexualidad también las nociones en torno a lo que se considera una persona es puesta en duda por la aparición de personas que no siguen la norma (Butler, 2007: 71-72). Es a través de la matriz de "inteligibilidad heterosexual" (Ibídem) que se fijan y reproducen nociones lineales y acumulativas en torno al sexo, el género y la orientación del deseo.

Las identidades sexuales y de género disidentes designarán aquí por lo tanto a aquellas identidades que rompan de distinta forma, desalineen, desestabilicen la aparente unicidad entre género, sexo, identidad de género, orientación del deseo, eroticidad, afectividad, etc. de la matriz de inteligibilidad heterosexual (Butler, 2007) en que se basan las relaciones sociales actuales y que se conciben como lineales y acumulativas. Son además disidentes respecto a un "pensamiento heterosexual" (Wittig, 2006) que realiza una interpretación totalizadora de la realidad en sus múltiples facetas y de todos los fenómenos. Un pensamiento opresor y universalista en la producción de sus relatos y sus leyes que aparecen como aplicables a todos lxs sujetxs, en todas las épocas (Wittig, 2006: 52).

Es por ello que las identidades sexuales y de género disidentes en esta investigación se conciben de manera metafórica como fronterizas (Anzaldúa, 2016). Que las identidades disidentes remitan a fronteras y se politicen en esas fronteras apela a esos espacios vagos e indefinidos que sugieren, llenos de contradicciones que permiten complejizar las nociones fijas en torno a las identidades y conceptualizarlas como espacios en construcción. Las identidades sexuales y de género disidentes "son" fronteras y poseen fronteras. Como identidades construidas y encarnadas por lxs sujetxs tiene efectos materiales y simbólicos en 
la vida de las personas. Prescriben modos de habitar, modos lingüísticos, modos de socializar, jerarquías y formas culturales particulares (Sívori, 2005).

En el presente artículo abordaremos algunas de estas fronteras que presentan las identidades no solamente en cuanto límite y posibilidad sino además como formas de politizar las identidades que implican movimientos y contradicciones, y además diversas formas de experimentarlas y de generar estrategias en torno a ellas.

\section{Los "lugares" de la ciudad}

Los lugares de la ciudad que serán abordados en relación a la politización de las identidades sexuales y de género disidentes serán entendidos como: "nodos" o articulaciones específicas de distintas relaciones y prácticas sociales y estarán anclados a un contexto geográfico e histórico (Massey, 2004). Serán el resultado de una mezcla de relaciones e intercambios que implican un "sentido global de lo local" (Massey, 2004: 79) que alude principalmente a cómo en la actualidad cada localidad está integrada por relaciones globales, mediadas, interconectadas, que las exceden geográficamente. De manera que cuando nos referimos a los lugares se hace alusión a relaciones internas y externas, globales y locales que la componen al mismo tiempo.

Siguiendo a Massey (2012) los lugares se caracterizan por cuatro atributos principales: primero, los lugares al ser definidos como conjuntos de interacciones sociales, siempre se desarrollan en términos de procesos y no como algo acabado; segundo, los lugares no tienen fronteras que sean visibles sino relaciones con lo que puede ser un exterior; tercero, los lugares no tienen identidades únicas y específicas; cuarto, hay una especificidad del lugar que está dado por cómo se dan las relaciones sociales en ese lugar y no en otro (2012: 127-128).

Es importante subrayar que los lugares poseen identidades culturales que no son fijas, sino que se adquieren a través de las interacciones sociales en el tiempo, éstas siempre están en proceso de cambio y de conformación en interacción con lxs sujetxs.

Esta manera de imaginar la "identidad" puede conducirnos a múltiples direcciones. Primero puede conducirnos a explorar dentro del lugar, hacia una apreciación de su complejidad interna, es decir una apreciación de las multiplicidades, de la diversidad de cada identidad. Esto es, el lugar como punto de encuentro, como negociación constante, como hibridismo ineludible (Massey, 2004:79).

La relación de lxs sujetxs con los lugares, así como sus experiencias de exclusión o de inclusión, estarán vinculadas con dinámicas de poder que se materializan en los espacios 
concretos, normas sociales que devienen en normas espaciales, que determinará en definitiva quién pertenece a un determinado lugar o quién queda excluido del mismo (McDowell, 2000: 15). La exclusión o inclusión no se da sólo en términos espaciales sino también subjetivos y simbólicos de la vida en sociedad y estará vinculado con las relaciones sociales que se dan en los lugares; relaciones políticas, de identificación, de expresión comunitaria, de posibilidad de reconocimiento mutuo con la diversidad en sentido amplio, la expresión y la integración cultural (Segovia, 2009).

Los lugares tienen significados y adquieren significados, es decir, entre lxs sujetxs y los lugares se da una relación que es productora de subjetividades. "Esto forma identidades relacionadas o vinculadas con el territorio y con el lugar, transformándolo en un espacio, un 'lugar practicado'. Los 'lugares practicados' son espacios que representan algo para los sujetos y que en sí mismos guardan un sentido para quienes los ocupan” (Hernández, 2016: 38).

Dentro de los significados que poseen y adquieren los lugares se encuentran los relativos al género y a la sexualidad. Los modos de habitar nuestros cuerpos, en relación con otrxs, en determinados espacios, tienen una relación con las características genéricas y sexuales de los mismos. Las relaciones de género y sexuales siempre están espacializadas (McDowell, 2000:101).

De esta forma los lugares se estructuran siguiendo las normas de género imperantes en la sociedad, las cuales varían de cultura a cultura y con el paso del tiempo. Los lugares son un reflejo de cómo se entiende y materializa el género en las relaciones sociales que ellos albergan y reproducen (Massey,1994: 40). Cada lugar tendrá maneras distintas de estructurarse en base al género y también de ser experimentado por lxs sujetxs en esas relaciones sociales que los conforman mutuamente.

Asimismo, en los lugares la arquitectura también tiene:

[...] un rol importante en la experiencia corporal de los individuos. La arquitectura es, entre otras cosas, un proceso de producción cultural de los cuerpos y las identidades sociales [...] al apuntar las formas de relacionamiento y circulación de los espacios (Sempol, 2018: 22).

Los modos de estructurar y construir los espacios físicos son también una manera de disponer y gestionar a las identidades en el espacio. 


\section{En terreno: Fabiana}

L - ¿Sola no salís?

F- No, muy raramente... sola rarísimo, no, aparte no salgo porque imagínate sola, y de noche, de día ya es bravo, imagínate de noche ...

L- ¿Te dicen cosas que no están buenas?...

F- De todo un poco, no sabes lo que te dicen acá, pa, las personas son remalas, te gritan de todo un poco. Tú vas caminando y te gritan ...

L- ¿Vas al almacén e igual?...

F- No. Más es en Sarandí ahí... los viernes, sábados y domingos ahí, pero en plazas así es cruel (Fragmento de entrevista a Fabiana, Rivera).

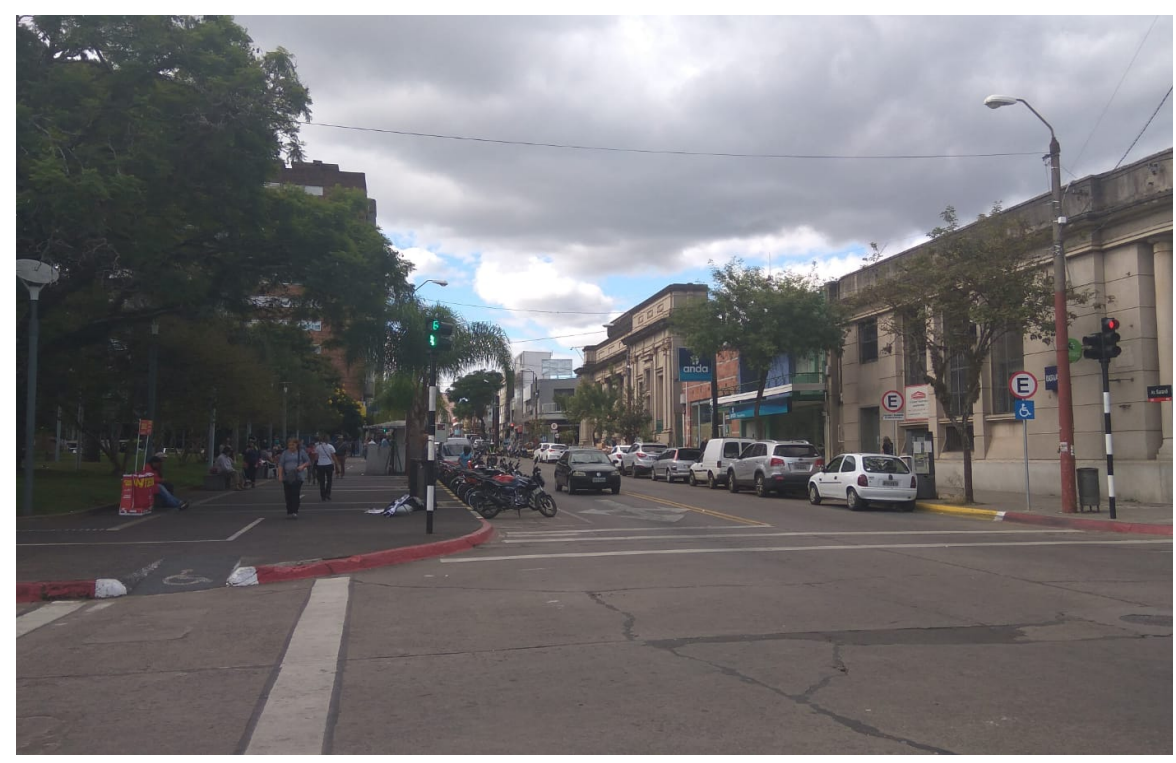

Foto 1: Plaza "General Gervasio Artigas” y calle Sarandí. Rivera, Uruguay. (Año 2016, Laura Recalde)

Fabiana es una mujer trans de 21 años que vive cerca del centro de la ciudad de Rivera. En el fragmento de la entrevista cuando se refiere a "Sarandí" hace alusión a la calle principal del centro, la misma tiene una extensión de aproximadamente 14 cuadras y allí se encuentran comercios de distinto tipo: Freeshops, Cafés, la Plaza: "General Gervasio Artigas", la Plaza: "Venancio Flores", distintas dependencias estatales, entre otros sitios. Sarandí termina en la calle 33 Orientales donde al cruzar ya nos encontramos en Santana Do Livramento, Brasil.

En el relato de Fabiana se observan varios elementos, su dificultad de transitar sola el espacio del centro de la ciudad, principalmente los días viernes, sábados y domingos, asociado a los 
horarios de la noche, dado que "ellos" son los que "salen más". Incluso menciona que es raro que salga sola también de día porque la gente le grita, la insulta por la calle, se burlan.

Yo soy una persona que no me dejo abatir por nada, tipo nada, me dicen puto, pongo las espaldas, a que no me pese (Fragmento de entrevista a Fabiana, Rivera).

Luego de dejar el liceo por varios años, por las burlas que sufría, lo retoma en el turno nocturno en donde se siente más cómoda. De todas maneras, duda de continuar con sus estudios por el temor que siente al transitar sola las calles en el horario de la noche, para volver a su casa.

L- ¿Cómo te está yendo?

F- Por ahora bien, el tema es salir, porque cuando veo acá, agarro mucha calle oscura, viste, a mí me cuesta venir tipo, porque es peligroso andar a las 11 de la noche, y más, yo salgo a las 11.

L- ¿Vas a algún liceo de por acá?

F- Sí, al 8. Y entonces, ahora no es tanto, pero imagínate en el invierno que no ves a nadie con esos fríos y salir a las 11 es... y aparte los viernes que son días que se toma, salen...

L- ¿Te da miedo?

F- Sí, demasiado.

L- ¿Salís antes o algo?

F- Es lo que a mí me pone un obstáculo de seguir o no seguir, por ese miedo [...].

(Fragmento de entrevista a Fabiana, Rivera).

Me aclara que caminar por las plazas de la ciudad sola es "cruel" en cambio si va acompañada de su pareja o con otras amigas trans, en grupo, no se "meten" con ella, en sus palabras si vas sola "fuiste" 12 . Es importante en su relato cómo los grupos de personas que suelen agredirla verbalmente siempre aparecen en grupo y cómo esto se intensifica cuando ella está sola. Me relata además episodios en el liceo en donde le han ofrecido dinero a cambio de sexo. En su opinión las personas trans son vistas como un símbolo sexual.

F- [...] a veces lo que veo yo en Rivera, es que vos sos trans y las personas te dicen “¿cuánto?” tipo "cuánto por ta” y te dicen en la cara, las cosas horribles, tipo: “¿cuánto?” "100 pesos por tal" ¿me entendés? el otro día vino alguien en el liceo y me dijo: "te doy 300 pesos para tal cosa" no se puede, no se puede...

L- ¿Vos qué hiciste?

12 Es una expresión de uso común que alude a los peligros que pueden ocurrir en determinadas circunstancias, por ejemplo, el caminar sola por la calle. 
F- Tipo casi le rompí la cara, pero mal, porque ¿cómo te van a decir eso? Tú sos trans, no sos símbolo sexual, no sos un símbolo de que sólo querés... ¿me entendés? Yo no juzgo a las trans que tienen su trabajo en la calle, jamás, un día puedo hacer también, yo no estoy libre de eso, o sea que hoy no hago porque tengo una familia que me brinda todo (...)

(Fragmento de entrevista a Fabiana, Rivera).

Dado que el objetivo del artículo es abordar cómo lxs sujetxs politizan sus identidades sexuales y de género en los distintos lugares de la ciudad es menester, siguiendo a Massey (1994), abordar las relaciones y prácticas sociales que en los lugares se re-producen.

Según Goffman (2006) existe en la interacción social ciertos atributos que son esperados, previstos, sobre lxs sujetxs y que permiten categorizar a las personas, constituyendo lo que se llama "identidad esperada". Sobre este tipo de identidad se crean ciertas "expectativas normativas" que caracterizan en "esencia" a lxs sujetxs. Esta caracterización y expectativas van en detrimento de la "identidad real" que muchas veces no cumple con esas características.

Cuando una persona posee un atributo diferente a lo que la norma establece se produce un estigma, por este atributo desacreditador la persona que lo posee ve en riesgo su estatus como tal. La "matriz de inteligibilidad heterosexual" (Butler, 2007) exige la existencia dentro de la norma o de lo contrario, pone en riesgo su propia existencia. Vale aclarar que no es el atributo en sí la que la hace poseedora del estigma sino las relaciones que en la interacción la constituyen como tal. De esta manera se produce una división entre quiénes se apartan de la norma y quiénes no lo hacen (Goffman, 2006).

En el relato de Fabiana vemos cómo ella, como persona trans, con una identidad de género distinta a la que le fue asignada al nacer, tiene un estigma que es visible, no se puede gestionar a través de un ocultamiento, y la coloca como poseedora de un atributo desacreditador. Es decir, ella por su identidad de género se posiciona de otra manera frente a la norma y frente a las expectativas socialmente esperadas. Su estigma además de colocarla en ese sitio "no totalmente humano" (Goffman, 2006:15) la descalifica y la vuelve principalmente ese atributo y no otros que también posee pero que quedan en un segundo plano.

Podemos agregar siguiendo a Radi (2018 s/n) que está operando un cisexismo que se basa en un “(...) sistema de exclusiones y privilegios simbólicos y materiales vertebrado por el prejuicio de que las personas cis son mejores, más importantes y más auténticas que las personas trans" permeando en este caso las formas en que las personas están o no en los espacios privilegiando a las personas cisgéneros. 
Asimismo, es a través de la relación social que se da en los lugares, por ejemplo, la plaza, y con quiénes frecuentan ese sitio, que su estigma se vuelve enunciable, por ejemplo, a través del insulto, y que traerá consecuencias en el modo de transitar los lugares por parte de Fabiana.

Siguiendo a Goffman (2006) podemos mencionar cómo "El individuo estigmatizado tiende a sostener las mismas creencias sobre la identidad que nosotros" (2006: 4) es decir, también la persona estigmatizada está inmersa en un mundo simbólico que la reconoce desde el sitio de estigmatizada y que la lleva en definitiva a actuar en función de él, como parte de su identidad social. En el caso de Fabiana el estigma que posee, y las consecuencias que trae consigo su puesta en discurso y lo que simboliza en términos de peligro, hace que su tránsito por la ciudad se vea restringido y que ella actúe en función del estigma.

Fabiana menciona cómo prefiere no frecuentar sola la plaza principal de la ciudad, la “General Gervasio Artigas”, los días viernes, sábados y domingos en horarios de la noche, aunque también le sucede durante el día. Esto permite también observar cómo los lugares no son los mismos según los días y horarios en que se transita y que también sus usos y funciones cambian de acuerdo a estas características. Podemos asumir que estos días del fin de semana, por lo relatado por ella, son días en donde la gente se reúne y sociabiliza, se toma alcohol, y las personas se quedan hasta la noche en grupos, generalmente gente joven. De esta manera también las personas que frecuentan los espacios según los días y los horarios son diferentes.

Los lugares "públicos" de la ciudad, las relaciones que se dan allí, poseen expectativas normativas sobre la identidad de género de las personas, de modo que al poseer un atributo que no está del lado de la norma, la cisgeneridad, lo que no se alinea con lo previsto, es marcado como distinto y en este caso esta "marca" tiene que ver, siguiendo con el ejemplo, con una alocución desde el lenguaje y a través del insulto, en forma de violencia verbal.

El enunciado ofensivo, según Butler (2009), da cuenta de la vulnerabilidad física y lingüística del sujeto, que están hondamente y complejamente relacionadas, y que tiene como telón de fondo la condición de reconocimiento mutuo que se da entre lxs sujetxs a través del lenguaje.

[...] ser el destinatario de una alocución lingüística no es meramente ser reconocido por lo que uno es, sino más bien que se le conceda a uno el término por el cual el reconocimiento de su existencia se vuelve posible. Se llega a "existir" en virtud de esta dependencia fundamental de la llamada del "otro" (Butler, 2009:22). 
Esta relación de vulnerabilidad respecto "del otro" es condición del sujeto hablante, tanto para aquel que habla como para aquel al que se le habla, ambos existen en el lenguaje y están constituidos por el lenguaje (Butler, 2009:57). Ahora bien, Butler distingue, por un lado, el acto por el cual se realiza un enunciado ofensivo o una amenaza y por otro, el hecho mismo de que esa amenaza sea realizada. De modo que son dos momentos distintos en donde no se tiene la certeza de si el acto de habla será eficaz o no pero que encierra en sí mismo esa posibilidad (Butler, 2009:28).

Es a través del insulto: "Puto" que Fabiana "entra" al lenguaje y es nominada al transitar por el lugar, marcando de este modo una relación de subordinación frente a un otro que la describe y a través del cual ella también se reconoce. El insulto, como nombre por el cuál es interpelada una persona, hace alusión, como todo acto de habla, a su performatividad (Butler, 2007), es decir, describe una serie de actos por los que ese nombre es conceptualizado como insulto, actualizando en su enunciación una convención que le da ciertos significados sociales.

En este caso una situación de vulnerabilidad de las identidades trans está marcada por un insulto que ignora desde el inicio su identidad de género de mujer, la ridiculiza y actualiza en su enunciación una serie de prejuicios en relación directa a su orientación sexual, siempre desde una desacreditación y una abyección que es previa.

Según Butler la interpelación, en este caso a través del insulto, tiene como objetivo "indicar y establecer a un sujeto en la sujeción, producir sus perfiles en el espacio y en el tiempo. $\mathrm{Su}$ operación repetitiva tiene el efecto de sedimentar esta "posición" en el tiempo" (2009: 62) de modo que al enunciarse también se actualiza su convención por lo que fue enunciado en una primera instancia. En este caso, además de reproducir una situación de subordinación, el insulto desencadena, por el riesgo que implica en términos de una acción potencial, una reacción de Fabiana sobre cómo transitar por la ciudad en ciertos días y horarios. Es decir una reacción en su materialidad corporal en relación al espacio.

De este modo Fabiana asume ese reconocimiento que hace de sí ese otrx y actúa en función de ello reforzando los efectos de exclusión que éste genera. Butler (2009) menciona cómo el lenguaje tiene la capacidad de "herirnos" dado que somos seres lingüísticos y estamos insertos en el lenguaje, y que esto da cuenta de los efectos mismos que el enunciado ofensivo posee. Fabiana describe este tránsito por la ciudad en términos de crueldad, una manera de enunciar los efectos que tiene en su persona lo que experimenta en el tránsito por los espacios. 
A propósito del enunciado ofensivo la autora enfatiza que como en cualquier acto lingüístico los partícipes están en mutua dependencia, y que al hacerlo también el cuerpo de ambxs está involucrado. La misma performatividad que da sustento en un primer momento a la situación de subordinación, a través del insulto, puede pensarse para un movimiento y un cambio (Butler, 2009). "El cuerpo del hablante, como "instrumento" de una violenta y "retoricidad", excede las palabras dichas y pone de manifiesto que el cuerpo a quien el habla se dirige no puede seguir estando (al menos no siempre enteramente) bajo control” (Butler, 2009:32).

De este modo la vulnerabilidad corporal y lingüística de ambxs está en juego y potencialmente puede ser resignificada. La acción implica un contexto y ciertas herramientas para llevar adelante este proceso de resignificación que entiendo no es siempre viable, ni tampoco recomendable por las violencias que puede implicar, pero que en definitiva puede ayudarnos a pensar otros posibles movimientos.

Fabiana relata haber vivido episodios violentos que tienen que ver con la asociación de ser una persona trans y en consecuencia ejercer el trabajo sexual. Si bien en Uruguay la exclusión laboral hace del trabajo sexual el principal medio de sustento de la población trans, en el caso que relata Fabiana se trata de otro estigma que asocia directamente el ser trans con ser trabajadora sexual y que habilita, no importa dónde ni cuándo, una oferta de sexo pago sin mediar previamente consentimiento con la persona implicada.

Este acto que en un contexto de ejercicio del trabajo sexual puede ser ordinario, sin éste y a la salida de una institución educativa se convierte en una situación de violencia. Dentro de los estigmas que posee la identidad trans se suma la sexualización de sus cuerpos en relación al trabajo sexual. Advertimos en el relato de Fabiana además cómo éste siempre es un horizonte de posibilidad en donde la clase social y la contención familiar son elementos importantes a la hora de ejercer o no ese trabajo.

Fabiana describe además que siente miedo al salir del liceo, al tener que atravesar las calles para llegar a su casa, a la noche. Describe su sentir en términos de peligro: el tránsito en soledad, la ausencia de gente, la oscuridad y las consecuencias que puede conllevar, hace que se cuestione el seguir o no con sus estudios secundarios.

En los contextos latinoamericanos actuales la tríada: miedo, ciudadanía y espacio urbano, son elementos que están presentes en la experiencia cotidiana de lxs sujetxs principalmente por el temor generalizado hacia los delitos, las agresiones y la inseguridad en general. Los Estados 
ante esta situación han reaccionado implementado medidas para garantizar e incrementar los derechos civiles de las personas, pero sin conseguir acabar con el miedo. Éste se va configurando como un modo contemporáneo de habitar urbano que posee una serie de características propias en los modos de acceder a la ciudad, de evitarla, de entenderla y de relacionarse con los demás; configurándose así cierto tipo de ciudadanía, definida por una negación (Segura, 2009).

En este contexto, poseer una identidad trans se inserta en una realidad ya de por sí compleja. Segura nos incita a pensar: “¿Qué papel juega el miedo en la configuración de los modos de pertenecer a un determinado colectivo? En última instancia, ¿qué relación existe entre miedo y ciudadanía?" (Segura, 2009:62). El autor habla de la "ciudadanía del miedo" para pensar una nueva subjetividad que denota modos de vivir en la ciudad y clasificaciones sociales que modelan las prácticas (Segura, 2009:65).

El caso de Fabiana muestra como el accionar desde un lugar de estigmatización, por las relaciones sociales que se reproducen en los lugares, tiene como consecuencia una restricción de sus derechos fundamentales en el desarrollo de su personalidad. Observamos además cómo a pesar de las transformaciones legales que se han suscitado en el país efectivamente el miedo modela las prácticas cotidianas en el tránsito por los lugares, siendo aplicable este el tipo de ciudadanía del miedo planteada por Segura.

\section{Paola}

L- Si van a la plaza, ¿están tranqui, se muestran?

$\mathrm{P}-\mathrm{Si}$, estamos tranquilas pero ya nos pasó sí de que nos quedaran mirando feo, en el cerro una vez que fuimos, el Cerro del Marco ${ }^{13}$, estábamos allá y llegó una muchacha y nos quiso correr de ahí, porque dijo que había niños chicos ahí y yo soy bien expresada pero cuando veo que tengo que ignorar cosas que dicen yo me quedo bien tranquila y ta, me retiro si tengo que hacerlo o me quedo tranqui.

L- ¿Y de ahí se fueron?

P- De ahí nos levantamos y nos fuimos porque ta.

L- Es que a veces no sabes que decir...

P- No sabés con quién te vas a estar metiendo... (...) Pasó muchas veces acá. Mi amigo el que falleció, fue víctima de una violencia, lo vieron con el novio y fueron unos borrachos

13- Desde el Cerro del Marco se puede observar tanto la ciudad de Rivera como la de Santana Do Livramento, se encuentra uno de los "marcos" históricos que separan ambas ciudades, la gente va allí a pasar la tarde y sociabilizar. 
quisieron pegarle, lo lastimaron en un ojo fue, pero ta en seguida se pararon ahí, pero siempre insultando.

L- ¿Así que acá está bravo?

P- Horrible, tanto acá como en Santana, que estamos con la frontera, tanto acá como en Santana

L- Acá me han dicho que es distinto porque la gente te conoce, no sé, ¿qué te parece a vos?

P- Es peor, si, vos vas a la esquina y decís un nombre y todos conocen a la persona, es complicada la sociedad de Rivera...

L- ¿Si? así que vos ves que no está bueno si sos trans, si sos gay...

P- Muy, muy, de menos [...]

(Fragmento de entrevista con Paola, Rivera).

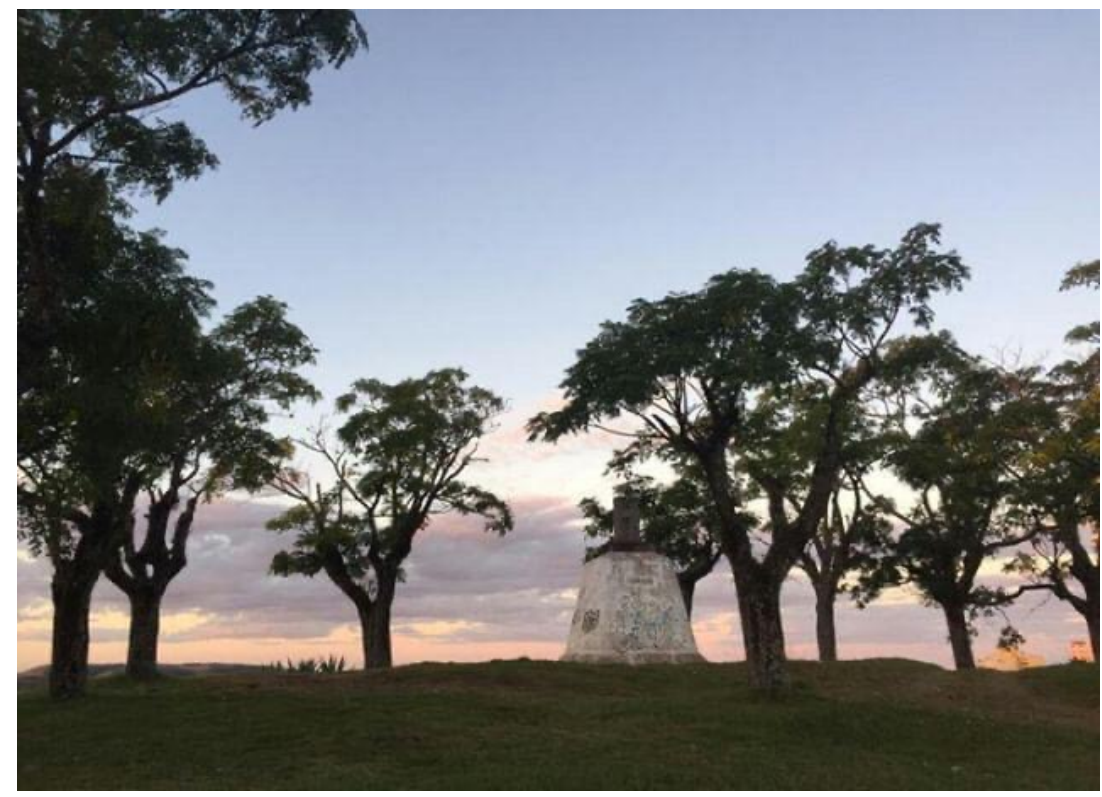

Foto 2: Cerro del Marco, Rivera-Uruguay. (Año 2016, Laura Recalde).

Paola tiene 18 años y se define como bisexual, ha tenido varias parejas mujeres, incluida la actual, y desde estas experiencias relata cómo ha sido su habitar la ciudad visibilizándose con ellas. Según su perspectiva si sos gay, lesbiana o trans, tanto en Rivera como en Santana do Livramento, es "horrible".

La frontera con Brasil, desde el punto de vista de Paola, pero también de otrxs entrevistadxs en Rivera, aparece como un espacio continuo en cuanto a ciertas costumbres comunes en ambos lugares. Destaca que en Livramento hay "más machismo" y que priman valores más 
tradicionales relacionados principalmente a la cultura gaucha de la zona que tiene mucho peso y que "afecta" a Rivera. Ésta aparece en el discurso como "influenciable" por las costumbres que provienen de Brasil, como ejemplo aparece el idioma, lxs riverenses hablan portugués comúnmente o DPU ${ }^{14}$ (Dialectos Portugueses del Uruguay) mientras que en Santana do Livramento no ocurre lo mismo con el español.

Paola me comenta de varios episodios de violencia hacia personas con identidad sexual disidente ${ }^{15}$ que han transcendido en estos años en Rivera y Santana.

P- Todo el tiempo que estuve con la mina ésta, y con la otra, y siempre pasó eso, que te queden mirando con cara fea... que te quieran... una vez me pasó estaba y una mujer nos inventó cualquier cosa, en vez de decirnos: "Por favor ¿se quieren retirar?” [...] estábamos en las escaleras acá y la piba salió de la casa diciéndonos que saliéramos de allí porque había cámaras, que los policías habían puesto cámaras y que no nos podían ver, y yo quede tipo: ¿cuál es el problema? Y yo hablé tranquila con la mujer esta que ta, me re quemó y le dije vámonos de acá.

L - ¿Qué le dijiste?

Y- Le dije que no podía decirnos nada porque yo estaba tranquila allí y ella: "no, que no las pueden ver, porque mis hijos", y yo: "qué tienen que ver tus hijos [...]

(Fragmento de entrevista con Paola, Rivera).

Paola relata que en varias ocasiones la han echado de lugares públicos y que han tenido para con ella y su pareja, en distintos espacios de la ciudad, gestos de desaprobación, episodios que en general involucran a personas mayores, pero también gente joven. A raíz de los episodios vividos ha pensado: "esto que estoy haciendo está mal" concluyendo finalmente que es su derecho estar con la persona que desee sin importar el lugar. Relata que por evitar "lío" muchas veces ha terminado cediendo ante las presiones de los demás.

En el liceo que concurre la situación es "más tranquila" pero las parejas del mismo sexo se esconden para estar juntas. Me comenta en general que hay muchas personas "LGBT" en la ciudad pero que es un tema que no se habla, que le gustaría que hubiera espacios para que la gente se informe "y se dé cuenta que es normal que no es anormal". Por lo conversado en rasgos generales según Paola no hay información disponible por ejemplo en temas de salud

14 Variedad dialectal del portugués que surge en las fronteras.

15 Hecho de violencia ocurrido en el año 2018 que trascendió en la prensa nacional: https://www.subrayado.com.uy/atacados-su-condicion-homosexuales-rivera-n503815

Esta noticia si bien fue en Santana Do Livramento por la cercanía de ambas ciudades también fue mencionado en varias oportunidades por distintas personas de Rivera: https://www.montevideo.com.uy/Noticias/Incendian-enSantana-do-Livramento-local-donde-iba-a-celebrarse-boda-gay-uc246687?plantilla=1391, http://radiouruguay.uy/rivera-denuncian- recurrencia-de-golpizas-homofobicas/ 
sexual o conocimiento sobre las nuevas legislaciones que están vigentes y amparan a la población.

Paola, como Fabiana, también posee un estigma (Goffman, 2006) que se gestiona de manera diferente. En este caso se hace visible cuando demuestra afecto hacia su pareja de forma pública, por ejemplo, en los episodios relatados en la plaza principal o en el Cerro del Marco, dejando en evidencia su orientación sexual. Esta visibilidad del estigma provoca la reacción de los presentes que actúan bajo otro orden de lo socialmente esperado y aceptado.

Podemos notar cómo al visibilizar el deseo sexual disidente éste se expulsa literalmente del espacio, hecho que denota cómo las relaciones, en este caso afectivo-sexuales, que se manifiestan en los lugares poseen ciertas normas en cuanto a las características de lxs sujetxs que las llevan adelante. Estas normas no son enunciadas explícitamente, de antemano, pero se vuelven visibles cuando ciertas personas, desde un lugar de privilegio, incitan al abandono del lugar a aquellxs que transgreden la norma, en este caso de la heterosexualidad.

En una sociedad que sólo considera «normales» las relaciones heterosexuales y familiares, aquellos individuos que no responden a esas expectativas se sienten incómodos en los espacios estructurados según las normas heterosexuales. Las efusiones de afecto heterosexual, por ejemplo, se consideran neutras o tolerables en restaurantes, cafeterías, hoteles y espacios públicos, pero no ocurre lo mismo con las muestras de cariño entre dos personas del mismo sexo (McDowell, 2000:96).

La demostración de afecto entre personas del mismo sexo en lugares públicos de la ciudad, su desaprobación y posterior expulsión da cuenta de este modo de una heterosexualidad obligatoria (Wittig, 2006) que permea las lógicas del espacio y que apela en su discurso a un orden social heterosexual.

Podemos observar como las miradas desaprobatorias, la apelación al orden policial y al control desde las cámaras, como amenaza para buscar la expulsión del lugar, están cumpliendo una función panóptica en donde desde una "anatomía política del cuerpo" se apela al disciplinamiento de los presentes en los lugares bajo un orden prefijado (Foucault, 2008: 241).

Siguiendo a este autor podemos mencionar que dentro de las sociedades disciplinarias existe una red intermedia de control, que no son instituciones propiamente dichas, que se encarnan a través de los individuos “disciplinando los espacios no disciplinarios" (Foucault, 2008: 248) espacios como la familia, los vecinos del barrio, entre otros. Esta función es posible porque 
los individuos son partes de la máquina panóptica que prolonga los efectos de su engranaje (Foucault, 2008:250).

Asimismo, siguiendo a Sabsay podemos notar cómo hay un imaginario socio-sexual hegemónico que sexualiza el espacio y articula la identidad. Los espacios se transforman así en modelos de subjetividad que son ideales y excluyentes y que son marcados materialmente con un indicador espacial (2011:72) construyendo lugares en donde algunos sujetxs son subalternos y otros privilegiados.

En el caso de Paola además de la apelación a la autoridad para justificar la expulsión, se manifiesta la presencia de "hijos" y "niños" como otro elemento importante. Esto sugiere que habría algo en la demostración de afecto de las parejas del mismo sexo, y no en las heterosexuales, que no puede ser visto por los menores de edad. Algo que está "mal", que interpretamos va en contra de las costumbres o de lo socialmente esperado en términos morales. Estos hechos hacen visibles el estigma y el prejuicio que estas prácticas siguen teniendo en la vida cotidiana.

[La] frontera-a la vez imaginaria y espacial-, no sólo garantiza, clasifica y jerarquiza las prácticas sociales, sino que opera de forma performativa, interpelando a los distintos sujetos sociales, y de este modo participa en la configuración del imaginario de cada identidad social (Sabsay, 2011:72).

Podemos notar cómo el imaginario socio-sexual (Sabsay, 2011) se articula en la espacialidad reforzando imaginarios de subordinación de las identidades sexuales y de género disidentes instaurando la idea de "la pureza de lo público", una especie de higienismo que actúa preservando las identidades hegemónicas de las disidentes.

Estás prácticas de restablecimiento de un orden moral-heterosexual se producen en un país que garantiza distintos derechos a las parejas del mismo sexo. Derechos que no impiden en la práctica la apelación a la misma autoridad legal-Estatal para garantizar un orden de tipo moral que va en clara contradicción con la garantía de los derechos mencionados. Observamos de este modo una distancia importante entre las leyes y la vida cotidiana de lxs sujetxs en donde existe un orden moral privilegiado y otro subalterno que sigue generando violencias y exclusiones.

Observamos además en el caso de Paola una actitud reflexiva en cuanto a la visibilización de su identidad sexual en los lugares y su vínculo con las demás personas que habitan los espacios. La politización de su identidad tiene modulaciones y va variando, reflexiona, se 
enoja, es expulsada de los lugares, pero continúa visibilizando su afecto desde un convencimiento a través de un paradigma de derechos. Aparece la rabia, la impotencia y en otras ocasiones una actitud contestataria más allá del resultado final. Estas oscilaciones también dan cuenta de cómo la manera de politizar la identidad sexual tiene que ver con las relaciones sociales que se producen en los lugares y también de los marcos interpretativos de lxs sujetxs que responden a contextos más amplios.

\section{Andrea y Fernanda}

Andrea y Fernanda nacieron, crecieron y viven en la ciudad de Rivera, tienen 33 y 34 años y hace aproximadamente tres años que son pareja y conviven. Ambas mencionan, en varias oportunidades, que no acostumbran estar de la mano o besándose en los lugares de la ciudad, demostrándose afecto públicamente.

A- $[\ldots]$ nosotras no andamos de la mano, ni nos estamos besando en la calle, para eso tenemos nuestra casa, no es que nos parezca mal pero no es de nosotras.

L- ok, entonces ¿ustedes no son de andar juntas de la mano en la calle?

F- No, no.

A- En la calle no.

F- Si tenemos que hacemos alguna caricia...

A- $[\ldots]$ o nos abrazamos, pero andar de la mano no, pero porque no tenemos esa costumbre.

L- Como que no les nace, no porque lo hayan hecho y les hayan dicho algo...

A- No, no.

F- A nosotras no nos pasa por eso, nos pasa por costumbre.

(Fragmento de entrevista Andrea y Fernanda, Rivera).

Ambas relatan que en sus trabajos todxs saben que son lesbianas y que en general no han tenido ningún episodio de discriminación por ello, que la gente ahora "acepta más". Andrea menciona cómo en la adolescencia sí sufría discriminación en el liceo, por parte de sus compañerxs, que pensaban que "capaz las podía contagiar" y fue una etapa complicada. Ahora ambas asisten al liceo nocturno, coinciden en que la situación es mejor que en su adolescencia pero que de todas maneras siempre hay miradas y "gente que no entiende". Forman parte además de la Iglesia Luterana en donde entienden que las aceptan, aunque nunca comunicaron explícitamente que son pareja, para ellas todxs saben dado que están siempre juntas y además conviven. 
Lo dicho y lo no dicho se va a repetir en su relato, específicamente respecto a su familia y otros espacios que transitan. Un elemento importante en su discurso es la religión que en el caso de Fernanda es un eje que transversaliza la actividad de su familia, específicamente la religión Evangélica, iglesia donde su padre y su abuelo son pastores.

F- Acá es: "pueblo chico infierno grande" $[\ldots]$

L- ¿Sí? me han dicho dos cosas, que estaba bueno porque son pocos y se cuidan... y por otro lado $[\ldots]$

A- Claro, nos conocemos con todos.

L - ¿Cómo lo viven ustedes?

- A- Yo que sé $[\ldots]$ yo bien [...]

F- Yo bien también, yo no ando gritando a los cuatro vientos pero no me importa si la gente sabe o no sabe.

L - ¿Y cuando salen a boliches todo bien, tranqui?

A- Si, todo bien.

F- Igual, como te digo, no somos de andar de la mano ni nada, boliches gay si porque te sentís más cómoda, pero en un boliche común yo no me siento cómoda no sé por qué [...] no sé por qué."

(Fragmento de entrevista Andrea y Fernanda, Rivera).

Actualmente están pensando en casarse y tener hijxs por medio de las técnicas de reproducción asistida, posibilidad que están evaluando cuando tengan una mejor situación económica y educativa. Sobre cómo perciben las nuevas legislaciones que las amparan, así como el clima general en la ciudad de Rivera siendo lesbianas me comentan lo siguiente:

A- Yo creo que todos los departamentos son iguales, pero acá aceptan bastante bien porque había bastantes señoras con sus hijos, con su familia, con sus esposos en la marcha [...] había bastantes que eran simpatizantes, solo ahí ves que un montón de gente te apoya, si bien hay un montón que te tira para abajo, hay un montón de gente que te apoya y que entienden o respetan, si no entienden por lo menos respeta.

L - Ahora los más jóvenes están más empoderados me parece [...]

F- A mí nunca me pasó de que me echaran, pero porque no nos estamos agarrando, tampoco nunca besé a una chica en público no sé, capaz que por eso no lo viví... los chicos de ahora quieren imponer algo que la gente está llevando con calma como que hay muchas personas que recién lo están aceptando y la juventud la mayoría lo que quiere es imponer hago, hago y chau $[\ldots]$ 
A- Cada persona tiene su tiempo no podés imponerle algo [...]

(Fragmento de entrevista Andrea y Fernanda, Rivera).

En la entrevista en general se puede observar cómo Andrea y Fernanda actúan tratando de evitar ser estigmatizadas (Goffman, 2006) al no visibilizar su orientación sexual en lugares públicos. La gestión de su identidad sexual es uno en el interior de su familia y trabajos, en donde la gente está en conocimiento de ésta, y otro en la iglesia, en donde asumiendo que los demás ya saben no hacen explícita la misma. De modo que hay una alternancia en cómo su identidad es gestionada y visibilizada según los ámbitos de los que se trate: "públicos” o "privados".

En lo que respecta a los lugares públicos de la ciudad ellas no manifiestan afecto, invisibilizando explícitamente su vínculo de pareja. El estigma de este modo no se produce y dado que el atributo desacreditador nunca es mostrado no genera sus posibles efectos. Para Andrea y Fernanda no demostrarse afecto públicamente, tomarse de la mano y besarse, se basa en la costumbre.

Giglia (2012), tomando el concepto de habitus de Bourdieu (1999), hace referencia a un "habitus socio-espacial" que estaría dado por los gestos por los que nos hacemos presentes en el espacio (2012: 16). Este tipo particular de habitus:

[...] ayuda a entender que el espacio lo ordenamos, pero también que el espacio nos ordena, es decir, nos pone en nuestro lugar, enseñándonos los gestos apropiados para estar en él, e indicándonos nuestra posición con respecto a la de los demás. El conjunto de prácticas repetitivas y automáticas con las cuales habitamos el espacio configura una dimensión de la experiencia que podemos denominar como de construcción y reproducción de la domesticidad (Giglia, 2012:16).

Si bien la autora hace hincapié en espacios de habitar no efímeros, podemos intentar aplicarlo a otros lugares que son importantes en la vida cotidiana como por ejemplo la plaza pública o el centro comercial de la ciudad, con los servicios que provee. Respecto a estos espacios ella desarrolla el concepto de "domesticidad", que estaría dado por: "la relación reiterada" con ciertos sitios que le dan el carácter de familiar, útiles, conocidos, sitios que son usados repetidamente y tienen determinados sentidos (Giglia, 2012:16).

La autora explicita cómo "El habitus permite el habitar y el habitar se hace mediante el habitus", en el proceso de domesticación, si bien podemos modificar el espacio que habitamos 
también éste puede condicionarnos en nuestra manera de domesticarlo y condicionar lo que se puede y no hacer en él (Giglia, 2012:17).

Andrea y Fernanda explicitan cómo en la "comodidad" de boliches "gais" no ocultan su vínculo afectivo como lo hacen en otros sitios públicos. Si bien ellas no reflexionan al respecto podemos nuevamente hacer alusión a cómo la norma en cuanto a la orientación sexual moldea sus prácticas y cómo en lugares en donde las mismas están "permitidas" este hecho no ocurre.

Podemos preguntarnos siguiendo a la autora si poseer una identidad sexual disidente, como en el caso analizado, implica la incorporación de un "habitus socio-espacial" específico (con sus distintas variables identitarias). Según Giglia (2012) todas las personas poseen un habitus socio-espacial, en este caso es interesante analizar si este tipo de habitus se estructura en base a una exclusión basada en la identidad sexual que tiene consecuencias en los modos de actuar en el espacio.

Es importante remarcar que son las relaciones sociales que se producen en los lugares los que van estructurando las formas de habitarlos. Los lugares nos "ordenan" cual son las pautas de comportamientos y gestos adecuados. Un ejemplo de esto puede ser la Marcha de la Diversidad de Rivera. En este contexto el espacio público se resignifica y se convierte en un espacio socialmente permitido para la visibilidad de las identidades sexuales disidentes. De hecho es a través de la adhesión a la marcha por parte de lxs riverenses que Andrea y Fernanda "miden" cuanto apoyo tienen de la población. La marcha en las calles de la ciudad, en el contexto de ese evento, "permite" la visibilidad de las identidades sexuales y de género disidentes. Esta resignificación del espacio puede entenderse como un paso hacia una apertura social y una mayor visibilización de las identidades sexuales, al mismo tiempo que marca la existencia de normas espaciales que también moldean y permean los espacios. Observando las dos aristas se evidencia el carácter social de los lugares, así como las contradicciones y articulaciones que los mismos albergan al mismo tiempo.

En el caso de Andrea y Fernanda la casa, el espacio privado, es el lugar privilegiado para demostrar su afecto. Una de ellas relata nunca haber besado a una mujer en "público" y que quizás por esta razón nunca fue "echada" de ningún sitio, ni vivió episodios de discriminación. El ámbito de lo doméstico aparece entonces como un espacio seguro en donde su vida amorosa tienen lugar. El hecho de ser dos mujeres además refuerza un mandato de 
género que reserva lo afectivo al ámbito doméstico y que además de alguna manera invisibiliza y desexualiza los lazos entre mujeres.

El relato de Andrea y Fernanda es un ejemplo de cómo la politización de la sexualidad es un gradiente que no es homogéneo y que se va alternado según las relaciones sociales que los lugares producen y reproducen. También pone de relieve como la politización tiene que ver con la propia subjetividad y se relaciona con distintos elementos: la edad, la familia, el contexto político social, la trayectoria vital y también las transformaciones que se han producido socialmente en torno a la sexualidad.

Si bien Andrea y Fernanda manifiestan su afinidad a las nuevas legislaciones y también participan en algunas de las actividades que realiza el colectivo Riversidad ${ }^{16}$, la forma de politizar su sexualidad tiene incorporada pautas de ocultamiento y de no confrontación para con lxs otrxs. Observamos como su accionar se alinea con paradigmas, que para las nuevas generaciones pueden responder a otra época, ya que conciben la demostración del afecto disidente exclusivamente en el ámbito del hogar, no mostrando públicamente la identidad o el afecto porque corresponde a la esfera privada y además porque no es aceptado por la mayoría.

En contraposición, el relato de Paola muestra cómo personas más jóvenes que han crecido con nuevas legislaciones en torno a la sexualidad disponen de otras herramientas para entender su propia identidad. Este hecho no es menor porque en la práctica permite una visibilización y politización pública que, aunque no está exenta de violencias, administra la identidad desde otros lugares, basada en un paradigma de derechos humanos.

Ambos relatos, con sus similitudes y diferencias, si bien podemos ubicarlos afines al posicionamiento de la diversidad sexual ${ }^{17}$, sin embargo esto no produce en la práctica formas homogéneas de politizar la identidad sino que muestra por el contrario como sus formas son diversas y oscilantes.

16 Único colectivo que milita temas referidos a la diversidad sexual en el departamento de Rivera.

17 En la investigación: "Las fronteras de la identidad. Politización de las identidades sexuales disidentes en el interior" uno de los hallazgos tuvo que ver con identificar dos formas de activismo en Rivera y Córdoba: la diversidad sexual y la disidencia sexual. La primera hace alusión a grupos que se conformaron mayoritariamente con la aprobación de ciertas legislaciones como por ejemplo las de Matrimonio Igualitario o las leyes de Identidad de género, o en ese contexto de promoción de derechos. Se caracterizan a grandes rasgos por mantener un diálogo con el Estado y por un posicionamiento basado en los Derechos Humanos. 


\section{Consideraciones finales}

A lo largo del artículo se han analizado diversas maneras de politizar las identidades sexuales y de género disidentes por parte de lxs sujetxs en los lugares de la ciudad de Rivera. En todos los casos esa politización desplegó estrategias específicas y diferenciales en la tramitación de la identidad y en la manera de ponerla en relación con otrxs.

Al comienzo caracterizábamos a los lugares como: i) conjuntos de interacciones sociales, que siempre se dan en términos de procesos y ii) sitios que no tienen fronteras que sean visibles sino relaciones con lo que puede ser un exterior (Massey, 2004). Sobre el primer punto, al analizar cómo lxs sujetxs politizan sus identidades sexuales y de género podemos concluir que efectivamente hacemos referencia a relaciones sociales que están en proceso. Las mismas siempre están ancladas en el espacio y llevan consigo significados y modos de ser practicados que varían.

En este sentido las formas de politizar las identidades disidentes no son homogéneas. A pesar de ciertos posicionamientos en común, encontramos distintas formas de politizar y gestionar la identidad que tiene que ver con trayectorias individuales. La "sutura" (Hall, 2003) que supone la identidad, muestra una relación compleja entre subjetividad y discursos sociales, en donde éstos últimos, en los casos analizados, tienen un papel muy importante en cómo efectivamente lxs sujetxs gestionan su identidad, visibilizándola, actuando a través de la norma de cis-heterosexualidad u oscilando entre ellas.

En relación al segundo punto, e intentando responder las preguntas realizadas al inicio, si bien los lugares de la ciudad no poseen fronteras visibles podemos observar cómo las relaciones sociales que se producen en ellos pueden entenderse como fronteras y límites físicos que impiden prácticas concretas. Estos límites no son fijos, pero marcan un límite de posibilidad sobre cómo las identidades sexuales y de género pueden efectivamente ser practicadas en los espacios, con las consecuencias que tienen para lxs sujetxs.

En los casos analizados aquellxs sujetxs que visibilizan su identidad, lxs que la ocultan por miedo al estigma o lxs que no pueden ocultarla tienen en común que despliegan distintas estrategias en cuanto a la politización de su identidad. Estas formas denotan como las identidades sexuales y de género disidentes, y sus formas de politización, son oscilantes, podemos decir fronterizas y tienen que ver con las particulares propias de lxs sujetxs, pero 
también con las relaciones sociales que se desarrollan en los propios territorios y con la nueva agenda de derechos puesta en práctica en el país recientemente.

Siguiendo a Segura (2009) abordar el derecho a la ciudad es una forma de analizar el acceso territorial a la ciudadanía, podemos decir en base a lo analizado, que existen formas diferenciales de acceder a la misma y a los derechos que ella implica. La "ciudadanía del miedo", es una figura que nos permite prestar atención a las formas del miedo contemporáneas y específicamente las que sufren algunos grupos en relación a la urbanidad.

El miedo como articulador de una serie de prácticas y relaciones sociales, en los espacios de la ciudad, nos incita a considerar las consecuencias que las emociones tienen en la vida cotidiana y al goce los derechos de las personas. Algunos conceptos que aparecen en los relatos repetidamente tienen que ver con lo "horrible", la "crueldad", la "costumbre", "visibilidad" y el "miedo". Estos sentimientos pueden rastrearse en las vivencias cotidianas de las personas entrevistadxs y en las formas de politización de su identidad sexual en los espacios públicos.

Observamos cómo los lugares de la ciudad, con las normatividades genéricas que suscitan, son performáticas (Butler, 2007) es decir re-instauran maneras esperadas y normativas de entender las identidades sexuales, bajo un orden heterosexual (Wittig, 2006) y además reproducen imaginarios sociosexuales (Sabsay, 2011) excluyentes y desiguales.

Los mecanismos de amenaza utilizados para expulsar a las personas de los espacios como son los policiales, aparecen para instaurar un orden moral en clara contradicción con las nuevas legislaciones que existen en el país, lo que nos hace preguntarnos en definitiva cuál es el que pesa más. Este hecho es importante porque en Uruguay carecemos de estudios que den complejidad a los modos de estar en el espacio de distintos colectivos sociales. Además, por las características históricas de nuestro país, las demandas de justicia generalmente son tramitadas a través de la aprobación de legislaciones, mecanismo utilizado por excelencia para paliar todas las desigualdades sociales que en este caso marcan un claro límite en cuanto a su peso en la vida cotidiana de las personas.

Finalmente analizar cómo se politizan las identidades sexuales y de género disidentes en los lugares de la ciudad de Rivera, de la mano de lxs propixs sujetxs, es una forma de aproximarnos al tipo de relaciones sociales que se producen y reproducen en territorios con otras lógicas que nos son las montevideanas. Poniendo de relieve que a pesar de contar con un 
contexto normativo muy favorable en el país aún es necesario un trabajo en el territorio que reduzca las brechas entre las normas morales y legales. 


\section{Referencias bibliográficas}

Anzaldúa, G. (2016). Borderlands. La frontera. The New Mestiza. España: Capitán Swing.

Argüello, S. (2013). "El proceso de politización de la sexualidad: identificaciones y marcos de sentido de la acción colectiva". En: Revista Mexicana de Sociología. Vol. 75. N², pp. 173200 .

Blas, R. (2018). ¿Qué es el tokenismo cisexista? En Revista Anfibia, disponible en: http://revistaanfibia.com/ensayo/que-es-tokenismo-cisexista/

Blas, R. (2018). "Políticas trans y acciones afirmativas en los ámbitos universitarios. Conversaciones necesarias para deshacer el cisexismo". En Revista Aletheia Vol. 10 N. ${ }^{\circ} 19$.

Bourdieu, P. (1999). Meditaciones Pascalianas. Barcelona: Anagrama.

Butler, J. (2006). Vida Precaria. El poder del duelo y la violencia. Buenos Aires: Paidós.

Butler, J. (2007). El género en disputa. El feminismo y la subversión de la identidad. España: Paidós.

Butler, J. (2009). Lenguaje, Poder e identidad. Madrid: Síntesis.

Butler, Judith (2010) Cuerpos que importan. Buenos Aires: Paidós.

Foucault, M. (2008). Vigilar y Castigar. Buenos Aires: Siglo XXI.

Foucault, M. (2011). Historia de la sexualidad. Buenos Aires: Siglo XXI.

Giglia, A. (2012). El habitar y la cultura perspectivas teóricas y de investigación. España: Anthropos.

Goffman, E. (2006). Estigma la identidad deteriorada. Buenos Aires: Amorrorotu.

Guasch, O. (1993). "Para una sociología de la sexualidad". En: Revista española de investigaciones sociológicas. No 64 , pp 105-122.

Guber, R. (2001). La etnografía, método, campo y reflexividad. Bogotá: Grupo Editorial.

Hall, S. (2003). “¿Quién necesita «identidad»?” En: S. Hall y P. du Gay (comps.) Cuestiones de identidad cultural. Buenos Aires: Amorrortu.

Hernández, J.O. (2016). "El último vagón”. El metro de la Ciudad de México: Heterotopías y prácticas homoeróticas. Tesis de Maestría, inédita. Disponible en: http://132.248.160.2:8991/pdf_pug01/000000287.pdf Último acceso: Setiembre de 2018

Massey, D. (1994). Espacio, Lugar y Género. Cambridge: Polity Press.

Massey, D. (2004). "Lugar, identidad y geografías de la responsabilidad". En: Treballs de la Societat Catalana de Geografia, N. ${ }^{\circ}$ 57, pp 77-84.

Massey, D. (2012). Un sentido Global del lugar. España: Icaria.

McDowell, L. (2000). Género, identidad y lugar. Un estudio de las geografías feministas. Madrid: Cátedra. 
Rubin, G. (1989). "Reflexionando sobre el sexo: notas para una teoría radical de la sexualidad". En: Vanee, Carole (coord.). Placer y peligro: explorando la sexualidad femenina. Madrid: Revolución.

Sabsay, L. (2011). Fronteras Sexuales. Espacio Urbano, cuerpos y ciudadanía. Paidós: Buenos Aires.

Sabsay, L. (2013). "Dilemas queer contemporáneos: ciudadanías sexuales, orientalismo y subjetividades liberales. Un diálogo con Leticia Sabsay". En: Revista Íconos. Revista de Ciencias Sociales. Núm. 47, pp. 103-118.

Segovia, O. (2009). "Convivencia en la diversidad: una mirada de género al espacio público" En: A. Falú (ed.) Mujeres en la ciudad. De violencias y derechos. Red Mujer y Hábitat de América Latina. (pp. 145-162). Chile: Ediciones SUR.

Segura, R. (2009). "Paisajes del miedo en la ciudad. miedo y ciudadanía en el espacio urbano de la ciudad de la plata". En: Cuaderno Urbano. Vol. 8 - No 8. pp. 59 - 91.

Sempol, D. (2013). De los baños a la calle. Montevideo: Debate.

Sempol, D. \& Montano, M. (2018). Baños públicos. La última segregación. Baños públicos moral, género y sexualidad en Uruguay. Montevideo: Intendencia Municipal de Montevideo (IMM).

Sívori, H. (2005). Locas, chongos y gays. Sociabilidad homosexual masculina durante la década de 1990. Buenos Aires: Antropofagia.

Vance, C. (1997). "La antropología redescubre la sexualidad: un comentario teórico". En: Estudios Demográficos y Urbanos, Vol. 12, No. 1/2, pp. 101-128.

Weeks, J. (1998). Sexualidad. México: PUEG-UNAM/Paidós.

Wittig, M. (2006). El pensamiento heterosexual y otros ensayos. España: Egales. 